Pesquisa e Reflexão em Educação Básica

\title{
O desafio da juvenilização em classes de alfabetização de jovens e adultos
}

Deivid de Souza Soares ${ }^{1}$

\begin{abstract}
Resumo:
O presente artigo teve como objetivo geral analisar como a juvenilização da Educação de Jovens e Adultos pode afetar o processo de alfabetização em duas escolas públicas que oferecem tal modalidade de ensino nos municípios de Canoas (RS) e Porto Alegre (RS). Quanto aos caminhos metodológicos, foi desenvolvida uma pesquisa qualitativa, de campo, que fez uso de um questionário como instrumento de coleta de dados, aplicado a duas professoras alfabetizadoras de jovens e adultos, tendo-se a análise de conteúdo como recurso metodológico para analisar os dados emergentes da pesquisa. Os principais resultados do estudo apontaram que a juvenilização na EJA é uma realidade presente no cotidiano da sala de aula. Constatamos, também, que para contemplar os jovens nas classes de alfabetização, é necessário que exista a disponibilidade do diálogo, para que assim possa ser construído um ambiente escolar que respeite a multiplicidade de formas de ser jovem, bem como a diversidade encontrada nesta modalidade de ensino.
\end{abstract}

\section{Palavras-chave: \\ Educação de Jovens e Adultos. Juventudes. Alfabetização.}

\section{The challenge youthfulness in youth and adult literacy classes}

\begin{abstract}
This article aimed to analyze how the youthfulness of Youth and Adult Education can affect the literacy process in two public schools that offer this type of teaching in the municipalities of Canoas (RS) and Porto Alegre (RS). As for the methodological paths, a qualitative, field research was developed, which used a questionnaire as a data collection instrument, applied to two young and adult literacy teachers, using content analysis as a methodological resource to analyze the results emerging research data. The main results of the study pointed out that youth in EJA is a reality present in the classroom. We also found that in order to contemplate young people in the literacy classes, it is necessary to
\end{abstract}

1 Mestre em Educação, Professor na Prefeitura Municipal de Canoas. E-mail: deividdesouza@yahoo.com.br. ORCID iD: http://orcid.org/0000-0003-0434-3425.

2 Mestra em Educação, Professora na Prefeitura Municipal de Canoas. E-mail: raquelameliasantos@gmail.com. ORCID iD: http://orcid.org/0000-0003-4686-0367.

3 Doutor em Educação, Bolsista PNPD/CAPES. E-mail: mendes.guilherme234@gmail.com. ORCID iD: http://orcid.org/00000001-9086-669X. 
have the availability of dialogue, so that a school environment can be built that respects the multiplicity of ways of being young, as well as the diversity found in this modality of teaching.

Keywords: Youth and Adults Education. Youthfulness. Literacy.

\title{
El reto de la juvenilización en grupos de alfabetización de jóvenes y adultos
}

\begin{abstract}
Resumen: El presente artículo tuvo como objetivo general analizar como la juvenilización de la Educación de Jóvenes y Adultos puede afectar el proceso de alfabetización en dos escuelas públicas que ofrecen tal modalidad de enseñanza en los municipios de Canoas (RS) y Porto Alegre (RS). Cuanto a los caminos metodológicos, fue desarrollada una investigación cualitativa, de campo, que hizo uso de un cuestionario como instrumento de recopilación de datos, aplicado a dos profesoras alfabetizadoras de jóvenes y adultos, teniéndose el análisis de contenido como recurso metodológico para analizar los datos emergentes de la investigación. Los principales resultados del estudio apuntaron que la juvenilización en la EJA es una realidad presente en el cotidiano de la clase escolar. Constatamos, también, que para contemplar los jóvenes en los grupos de alfabetización, es necesario que exista la disponibilidad del diálogo, para que así pueda ser construido un ambiente escolar que respete la multiplicidad de formas de ser joven, bien como la diversidad encontrada en esta modalidad de enseñanza.
\end{abstract}

Palabras clave: Educación de Jóvenes y Adultos. Juventudes. Alfabetización.

\section{Introdução}

O presente artigo apresenta resultados da pesquisa de cunho qualitativo desenvolvida ao longo dos meses de julho a novembro de 2017 - tendo como campo de estudo a alfabetização de Jovens e Adultos e o problema de pesquisa "como a juvenilização da Educação de Jovens e Adultos afeta o processo de alfabetização em escolas públicas dos municípios de Canoas (RS) e Porto Alegre (RS)?". Para guiar o estudo foi elaborado o seguinte objetivo geral: analisar como a juvenilização da EJA pode afetar o processo de alfabetização, em duas escolas públicas que oferecem tal modalidade de ensino, nos municípios de Canoas (RS) e Porto Alegre (RS).

Buscando responder esse problema, foi desenvolvida uma pesquisa de campo com abordagem qualitativa, coletando dados através de questionário. Tal estudo foi realizado em duas escolas públicas, em cidades da região metropolitana, sendo uma localizada na cidade de Porto Alegre - capital do Estado do Rio Grande do Sul -, no bairro Lomba do Pinheiro e a outra em Canoas, no bairro Guajuviras. Os sujeitos da pesquisa foram duas professoras alfabetizadoras que atuam na Educação de Jovens e Adultos - EJA. A escolha de tais instituições foi motivada pela experiência profissional dos pesquisadores, que segundo Gil (2008), quem realiza o estudo tem, por conveniência, a possibilidade de selecionar o seu lócus analítico-investigativo, uma vez que poderá ter maior acessibilidade aos dados.

Isto posto, destacamos que este artigo está dividido em quatro seções. A primeira corresponde ao aspecto introdutório da investigação. A segunda apresenta, por meio dos referenciais teóricos, um olhar para o contexto da EJA no Brasil, para os conceitos de alfabetização e escrita sobre os sujeitos e o processo de juvenilização da EJA. Na sequência deste, encontra-se a parte metodológica do artigo, bem como a análise dos dados coletados através da pesquisa. Dando continuidade, estão as considerações finais, onde buscamos fazer uma "costura" das principais ideias contidas nesse artigo. Por fim, apresentamos as referências que serviram de base fundante deste trabalho. 


\section{A educação de jovens e adultos: reflexões iniciais}

Pensar a Educação de Jovens e Adultos - EJA - no contexto da educação básica é refletir sobre a formação de estudantes que, por algum motivo, não concluíram seus estudos na idade prevista ${ }^{1}$. São jovens e adultos que não conseguiram adaptar-se ao ensino regular e/ou foram excluídos do sistema regular de ensino, seja pelas dificuldades de aprendizagem, pela necessidade de vincular-se precocemente ao mundo do trabalho, não apenas como uma possibilidade de auxiliar em casa, mas, também, como forma de vivência da condição juvenil (DAYRELL, 2002), entre outros motivos que, por um determinado período, os afastaram de suas trajetórias formativas. Conforme os dados apontados pelo Instituto Brasileiro de Geografia e Estatística - IBGE - no ano de 2017, o Brasil contava com 7\% de jovens, com 15 anos ou mais, analfabetos, na região sul 3,62\% (IBGE, 2018). O estudo ainda aponta que:

Cabe lembrar ainda da alfabetização de jovens e adultos (AJA) que busca promover a superação do analfabetismo entre pessoas de 15 anos ou mais de idade. Em 2017, 118 mil pessoas frequentavam tal curso, valor menor do que o de 2016, 153 mil pessoas. Do total de estudantes na alfabetização e educação de jovens e adultos, 95,5\% frequentavam a rede pública em 2017. Entre aquelas que frequentavam cursos presenciais do ensino fundamental, $85,2 \%$ frequentavam o turno noturno (...). (IBGE, 2018, p. 8).

Nesse sentido, desde a promulgação da Declaração Universal dos Direitos Humanos (DUDH ${ }^{3}$ ) (UNESCO, 1948), a educação básica é entendida como um direito social e fundamental, que deve ser assegurado aos cidadãos, de modo a possibilitar a sua escolarização para o desenvolvimento integral do sujeito, bem como a aprendizagem de práticas cidadãs e de qualidade para o desenvolvimento humano, social e profissional (UNESCO, 1948). Nesta perspectiva, os marcos regulatórios nacionais e internacionais vêm, a cada novo período, projetando a educação como uma necessidade para o avanço da atual sociedade do conhecimento (SANTOS, 2018).

Dessa forma, ao focalizarmos nossa preocupação para com a EJA, no âmbito de formação de jovens e adultos, nos faz refletir essa modalidade de ensino como uma alternativa para a garantia desse direito aos cidadãos brasileiros, durante o seu processo de reinserção no contexto escolar. Vários são os cenários presentes na EJA, os quais nos exigem um olhar atento para a produção do conhecimento sobre essa modalidade, como por exemplo, estudantes trabalhadores; os que são arrimo de família; os que ainda não foram alfabetizados ou são analfabetos funcionais; os que retornaram em virtude das exigências do mercado de trabalho; os jovens que não se adaptaram ao ensino regular, dentre muitos outros cenários possíveis. Corroborando essa ideia, Lemos (2017, p. 21) afirma que:

As políticas públicas de universalização do acesso ao Ensino Fundamental registram avanços recentes na história da educação em nosso país. Porém, há um número significativo de adultos e idosos que, em sua infância, não ingressaram na escola ou dela foram excluídos muito precocemente. Esse grupo de jovens e adultos fica constituído como uma parte do público da EJA, instituída como uma modalidade da Educação Básica, com currículo, sujeitos e metodologias próprias, a partir da LDB 9394/96. Outra parte tem sido de jovens que, mesmo tendo acesso e permanência na escola na idade regulamentar, não tiveram o aprendizado esperado e extrapolam a idade prevista legalmente sem a conclusão do Ensino Fundamental.

\footnotetext{
1 Optamos por utilizar esse termo "idade prevista", uma vez que, nem sempre, a idade certa - como anunciado nos documentos normativos da educação básica (BRASIL, 1996, 2018) - caracterize, no nosso entendimento, uma maneira mais democrática quanto aos tempos e modos de aprendizagem.

2 Dados disponíveis em: https://biblioteca.ibge.gov.br/visualizacao/livros/liv101576_informativo.pdf.

3 Para a leitura na íntegra do documento, acesse: https://nacoesunidas.org/wp-content/uploads/2018/10/DUDH.pdf.
} 
Consoante a essa perspectiva, a EJA necessita pensar a formação do estudante ao longo da vida, trazendo uma visão de que as aprendizagens devem ser abarcadas nesse ambiente de modo mais próximo à realidade estudantil (UNESCO, 2000, 2015; OEI, 2008). Necessita considerar, ainda, que os estudantes chegam com suas especificidades, fragilidades e conhecimentos prévios que podem e devem ser incrementados aos processos de ensino-aprendizagem. Para Lemos (2020, p. 15):

E também é possível perceber que, apesar de hoje podermos contar com materiais didáticos de qualidade elaborados especificamente para esta modalidade, que levam em conta a especificidade da EJA, ainda é possível encontrar práticas infantilizantes e centradas na memorização e repetição.

Diante de tal panorama, Soares (2002) destaca que, atualmente, no Brasil, estamos passando por uma transição das práticas antigas ${ }^{4}$ como a da "educação supletiva" para uma nova concepção de Educação de Jovens e Adultos, marcada pela educação popular (FREIRE, 1996), convivendo na prática de sala de aula. Cabe ressaltar que a EJA, no Brasil, tem seus pressupostos baseados na educação popular, tendo Paulo Freire como um dos precursores do movimento, considerando o diálogo, a interação, o desenvolvimento da autonomia e a busca da educação como prática de liberdade (BRANDÃO, 1984; FREIRE, 1983). Nesse sentido, com a redemocratização do Brasil foi dado continuidade aos princípios da educação popular, por meio da Lei de Diretrizes e Bases da Educação Nacional - LDB - de 1996, então, Educação de Jovens e Adultos passa a ser considerada uma modalidade de ensino (BRASIL, 1996).

Focaremos nossa análise neste parágrafo, no penúltimo item "As Diretrizes Curriculares Nacionais para EJA" que inicialmente fala da heterogeneidade dos estudantes da EJA, depois aborda que é importante reconhecer essa heterogeneidade ao elaborar o currículo, menciona ainda a importância da preparação docente para trabalhar na EJA e estabelece o currículo em duas partes. Soares (2002, p. 19) afirma que:

[...] uma base nacional comum, que garanta a integração, e outra parte, diversificada, que garante a contextualização. Determina, ainda, para cursos de EJA, a obrigatoriedade da oferta de uma língua estrangeira, e, para os exames a oferta obrigatória e inscrição facultativa.

No que tange ao conceito de alfabetização, podemos perceber que, teoricamente, existem diferentes conceitos. Para Soares (2004), as práticas que envolvam fonologia, fonética, grafema-fonema, sistema de escrita alfabética estão relacionados à alfabetização, enquanto práticas que envolvam o uso social e uma imersão da criança no mundo escrito podem ser práticas de letramento. A autora também procura conceituar o que é alfabetização, para poder aprofundar a discussão acerca dos dois conceitos, para Soares (2004, p. 15), alfabetização:

[...] faz parte a consciência fonológica e fonêmica, identificação das relações fonema-grafema, habilidades de codificação e decodificação da língua escrita, conhecimento e reconhecimento dos processos de tradução da forma sonora da fala para a forma gráfica da escrita.

Picolli e Camini (2012) apontam que, contrapondo as ideias de Soares (2004), Freire e Ferreiro, dois autores referência do campo da educação e da alfabetização, não adotam o termo letramento. O conceito de alfabetização de Freire (2011) vai muito além da decodificação, perpassando pela compreensão de mundo. 
[...] o ato de ler, que não se esgota na decodificação pura da palavra escrita ou da linguagem escrita, mas que se antecipa e se alonga na inteligência do mundo. A leitura do mundo precede a leitura da palavra, daí que a posterior leitura desta não possa prescindir da continuidade da leitura daquele. Linguagem e realidade se prendem dinamicamente. A compreensão do texto a ser alcançada por sua leitura crítica implica a percepção das relações entre o texto e o contexto. (FREIRE, 2011, p. 19-20).

Tornando assim a alfabetização como um ato político, propondo leitura de mundo, contextualizada, Silva (2009), ao apresentar as contribuições de Freire para alfabetização, destaca que a proposta pensada por ele possibilitava redescobrir o mundo, inserir-se completamente na sociedade, uma vez que é por meio da alfabetização que os que vivem à margem da sociedade podem lutar contra a sua realidade, fazendo uma crítica a ela e buscando mudanças. Nesse sentido, Kalman (2009) apresenta o relato de uma moça que mesmo tendo frequentado apenas dois anos a escola quando criança, ao descobrir que seu filho apresentava uma doença crônica no rim, foi aprendendo a ler bulas, estudar a fisiologia do corpo humano, entre outras coisas.

Picolli e Camini (2012) apresentam que, para Ferreiro, o uso de letramento é uma redução do conceito de alfabetização à codificação e decodificação.

$\mathrm{Na}$ contramão de tais concepções, a pesquisadora afirma que os sistemas de escrita são produtos históricos, sociais e culturais, não códigos, os quais se caracterizam por serem criações individuais, como o código Morse, por exemplo. (PICOLLI; CAMINI, 2012, p. 18).

Ao analisarmos o material fornecido pelo Governo Federal para a formação de professores alfabetizadores, através do Pacto Nacional pela Alfabetização na Idade Certa - PNAIC ${ }^{5}$ - percebemos que se compreende a alfabetização como algo além da apropriação da escrita alfabética. Busca-se fazer uma junção dos conceitos de letramento de alfabetização, pois segundo Albuquerque (2012), para a criança ser alfabetizada seria necessário dominar o sistema de escrita, bem como estar inserida na cultura escrita, utilizando suas aprendizagens para fazer parte do mundo escrito, entendendo e utilizando o uso social da escrita.

É importante considerar, no entanto, que a apropriação da escrita alfabética não significa que o sujeito esteja alfabetizado. Essa é uma aprendizagem fundamental, mas para que os indivíduos possam ler e produzir textos com autonomia é necessário que eles consolidem as correspondências grafofônicas, ao mesmo tempo em que vivenciem atividades de leitura e produção de textos. (ALBUQUERQUE, 2012, p. 22).

Esses conceitos sobre alfabetização também acabam por refletir nas práticas e conceitos de alfabetização na Educação de Jovens e Adultos. Para Fonseca (2001), os grandes paradigmas que estruturam a prática docente na EJA são o Construtivismo e a Educação Popular. Para a autora, a Educação Popular subsidia a prática dessa modalidade ao respeitar e utilizar as bagagens (backgrounds) dos educandos. "Para que a leitura de mundo anteceda a leitura da palavra, faz-se um mister que a cultura-mundo dos(as) alfabetizandos(as) adentre a sala de aula [...]" (FONSECA, 2001, p. 29). Já o construtivismo aparece quando percebemos que o conhecimento está na interação entre o objeto e o sujeito. Nessa perspectiva, apresentamos a próxima seção para discutirmos sobre os sujeitos da EJA - os estudantes - e o processo de juvenilização.

5 PNAIC - Pacto Nacional pela Alfabetização na Idade Certa, tratou-se programa que tinha como objetivo alfabetizar as crianças até os 8 anos, ao final do 3 o ano. Foram desenvolvidas diversas ações, entre elas, a formação dos professores atuantes no bloco de alfabetização, de 1으 ao 3ㅇ ano do ensino fundamental. Dando origem assim, aos cadernos do PNAIC, que contém textos escritos por especialistas da área, envolvendo letramento, alfabetização, consciência fonológica e sistema alfabético de escrita. 


\section{Os estudantes da EJA e o processo de juvenilização}

Os sujeitos da EJA quando retornam à escola, ou chegam pela primeira vez, já trazem sua bagagem pessoal, conceitos, valores, backgrounds. Não são estudantes como as crianças, porque possuem responsabilidades com a família, com o mundo do trabalho, entre outros. Por esse motivo devem ser tratados como adultos, ou seja, proporcionar práticas pedagógicas que possam ser significativas e considerem tais especificidades para esse público. Um professor, ao assumir sua turma de EJA, deve planejar e articular suas aulas, valorizando as experiências de vida trazidas pelos estudantes.

Os adultos possuem mais experiência que os adolescentes e podem ter acumulado uma maior quantidade de conhecimentos. Talvez sejam menos rápidos, mas podem oferecer uma visão mais ampla, julgar melhor os prós e os contras de uma situação e ter boa dose de criatividade. (BRASIL, 2006, p. 5).

Além dos saberes cotidianos citados acima, o MEC, no Caderno de EJA, no $1^{6}$, que centra a sua discussão acerca dos estudantes e alunas da EJA, nos apresenta outro saber importante, que o professor deve utilizar ao seu favor no processo de aprendizagem desses estudantes, que é o saber sensível, adquirido no contato com o outro, o saber do corpo, dos nossos sentidos. E que acaba no processo de aprendizagem, tanto com adultos como com as crianças, sendo, por vezes, perdidos. Até porque esse saber vem sendo pouco valorizado na vida moderna.

Os estudantes da EJA chegam na escola com grandes expectativas, normalmente, esperam que as aulas sejam realizadas de forma tradicional, com o professor como centro do saber e do cenário educativo. Isso se deve, geralmente, à memória de aula e escola que possuem. Nas capitais e regiões metropolitanas, é bastante comum encontrarmos uma variedade de estudantes, oriundos do interior, da própria cidade, de outros Estados e regiões do país. Segundo Brasil (2006, p. 12): "Se a origem de nossos estudantes é diversa, naturalmente, o acúmulo e a bagagem cultural deles também são".

Conforme afirma Moraes (2009), a Educação de Jovens e Adultos é marcada pela inclusão dos grupos minoritários ${ }^{7}$, seja no começo do século XXI ou em meados dos anos 40 , na sua criação, mesmo que não aparecesse nas políticas públicas explicitamente. Sendo assim, para a modalidade de Educação de Jovens e Adultos, nos parece que sempre foi mais fácil estar aberta para inclusão.

Os homens, mulheres, jovens, adultos ou idosos que buscam a escola pertencem todos a uma mesma classe social: são pessoas com baixo poder aquisitivo, que consomem, de modo geral, apenas o básico à sua sobrevivência: aluguel, água, luz, alimentação, remédios para os filhos (quando os têm). O lazer fica por conta dos encontros com as famílias ou dos festejos e eventos das comunidades das quais participam, ligados, muitas vezes, às igrejas ou associações. (BRASIL, 2006, p. 15).

Atualmente, encontramos uma grande parcela dos estudantes da EJA, sujeitos muito jovens, o mapa da Educação de Jovens e Adultos, no Estado do Rio Grande do Sul, elaborado por Alves, Comerlato e Sant'Ana (2018), aponta que a população, em Porto Alegre, maior de 15 anos chega a 1.144.434, desses, aproximadamente 25.979 são analfabetos, o que corresponde a $2,27 \%$. Já em Canoas, onde fica a outra escola participante de nossa pesquisa, os dados são de 251.189 maiores de 15 anos, onde 6.556 não estão alfabetizados.

6 Para a leitura do documento na íntegra, acesse: http://portal.mec.gov.br/secad/arquivos/pdf/eja_caderno1.pdf. 7 Entendidos aqui como pessoas com deficiência, de baixa renda, negros, pardos, índios, de diferentes gêneros, entre outros. 
Percebemos, que nos últimos anos houve uma redução no número de jovens matriculados na Educação de Jovens e Adultos no Brasil, segundo o Censo Escolar de $2018^{8}$ (BRASIL, 2018), no Brasil temos 3.545.988 estudantes matriculados, sendo 2.188.201 jovens ${ }^{9}$. No município de Canoas, temos um maior número de estudantes jovens, um total de 4014 matrículas, sendo que dessas, 3269 são de estudantes jovens. Esses dados apontam a necessidade de refletir sobre as práticas pedagógicas executadas e as metodologias aplicadas dentro da sala de aula. Sendo assim, os professores da EJA, hoje, devem adaptar-se ao novo público que estão recebendo. Além disso, a incompatibilidade de ritmos e perfis dos adolescentes, acaba contribuindo, também, para o afastamento dos adultos da sala de aula (SOARES, 2002).

Brunel (2004), ao falar sobre o processo de juvenilização na Educação de Jovens e Adultos, salienta que apesar da maioria dos jovens chegarem na EJA, assumindo para si o fracasso escolar, esse não lhe pertence apenas, visto que, também, a escola e a própria sociedade onde este jovem está inserido possuem suas responsabilidades. Já Carrano (2007) destaca a necessidade de pensarmos em uma escola que compreenda e trabalhe com a multiplicidade trazida pelos jovens, para a modalidade de ensino Educação de Jovens e Adultos. Para o autor:

Para enfrentar o desafio disso que temos chamado de 'juvenilização da EJA', deveríamos caminhar para a produção de espaços escolares culturalmente significativos para uma multiplicidade de sujeitos jovens - e não apenas estudantes - histórica e territorialmente situados e impossíveis de conhecer a partir de definições gerais e abstratas. Neste sentido, seria preciso abandonar toda a pretensão de elaboração de conteúdos únicos e arquiteturas curriculares rigidamente estabelecidas para os 'jovens da EJA'. (CARRANO, 2007, p. 2).

Tais perspectivas reforçam a importância que a escola possa reconhecer que existem diversas formas de ser jovem, de viver a sua juventude. A juventude é uma fase do processo de desenvolvimento humano, marcada por descobertas e construções de identidades na qual os grupos vão se formando por conta das afinidades entre eles (VIEIRA, 2012). Logo, pensar na ideia de juventude é construir uma reflexão complexa e que implica múltiplas possibilidades no que tange aos diferentes contextos que envolvem a construção das juventudes dos educandos.

Deste modo, Dayrell (2003, p. 42) destaca que:

Construir uma noção de juventude na perspectiva da diversidade implica, em primeiro lugar, considerá-la não mais presa a critérios rígidos, mas sim como parte de um processo de crescimento mais totalizante, que ganha contornos específicos no conjunto das experiências vivenciadas pelos indivíduos no seu contexto social. Significa não entender a juventude como uma etapa com um fim predeterminado, muito menos como um momento de preparação que será superado com o chegar da vida adulta.

Apresentamos essa concepção de juventudes na discussão do presente artigo para que consigamos compreender que ao atuar com esta modalidade de ensino, além de encontrarmos a diversidade entre jovens e adultos, existe, ainda, a diversidade entre os jovens. Sendo assim, concordamos com Carrano (2007) e Brunel (2004) quando falam da importância do diálogo e de ouvir os estudantes.

Neste ínterim, refletir sobre a prática de ensino na Educação de Jovens e Adultos é pensar em um trabalho que respeite a diversidade que encontramos nas salas de aula, ter o cuidado de planejar ações que sejam emancipadoras e que venham ao encontro da realidade dos estudantes.

8 Para realizar a leitura do documento na íntegra, acesse: http://download.inep.gov.br/informacoes_estatisticas/sinopses_estatisticas/ sinopses_educacao_basica/sinopse_estatistica_da_educacao_basica_2018.zip.

9 Tendo como referência que jovens são as pessoas com idade entre 15 (quinze) e 29 (vinte e nove) anos de idade, conforme o Estatuto da Juventude, Lei n.o 12.852 (BRASIL, 2013). 
Para tanto, avançamos na discussão apresentando a próxima seção, a qual aborda sobre o processo da juvenilização no contexto da alfabetização na concepção dos alfabetizadores.

\title{
A juvenilização e sua influência no processo de alfabetização: olhar de quem alfabetiza
}

O presente estudo, além da utilização de referenciais teóricos do campo da EJA e da alfabetização, constitui-se em uma pesquisa de natureza qualitativa, na qual utilizou como instrumento um questionário para coleta de dados. Severino (2007) caracteriza que a pesquisa qualitativa é uma oposição do método científico racional positivista ${ }^{10}$. E ao encontro a esse pensamento Najmanovich (2003, p. 34-35) apresenta que:

\begin{abstract}
Renunciar a ideia de um método único que nos conduza sempre à verdade, e que a garanta, não implica de nenhuma maneira que estamos dispostos a desistir da utilização de instrumentos ou dispositivos, técnicas e procedimentos. Só implica que não anteporemos o método à experiência, que não cremos que haja um só caminho ou um só dispositivo adequado para pensar, explorar, inventar... conhecer. Só renunciamos ao fetiche do método e podemos ainda desdobrar uma infinidade de dispositivos, construir caminhos, trilhas e estradas, ou escolher ir através do campo ou entre o mato, ou preferir o bosque a estrada. Renunciar ao método não implica cair no abismo sem sentido, mas abrir-se à multiplicidade de significados.
\end{abstract}

Pensando nisso, ao optarmos por realizar uma pesquisa qualitativa, não significa que ela não apresente método e rigorosidade, mas sim que não estamos "presos" a um fetiche do método, como apresenta a autora. Conforme salienta André (2001), é importante a existência de critérios para o desenvolvimento de pesquisas qualitativas. Esses deveriam ser comuns e específicos, de acordo com o tipo de pesquisa que será desenvolvida, sendo que essa construção deve ser coletiva e um processo de longa duração.

Para responder ao problema de pesquisa que apresentamos na introdução, foram selecionados os sujeitos participantes, então, optamos por analisar as respostas de duas professoras alfabetizadoras, em duas escolas públicas, uma na cidade de Porto Alegre e outra na cidade de Canoas. As escolas são da rede pública de ensino, sendo uma da rede estadual e a outra municipal, localizadas em zonas periféricas das cidades, Lomba do Pinheiro (Porto Alegre), vila Cafuncho e a outra no Bairro Guajuviras (Canoas). O instrumento de pesquisa selecionado para a coleta de dados foi um questionário, levando em consideração o tempo para análise das respostas, bem como o de exploração do material, percebemos que essa seria a melhor opção, Gil (2008, p. 121) conceitualiza o questionário:

[...] como a técnica de investigação composta por um conjunto de questões que são submetidas a pessoas com o propósito de obter informações sobre conhecimentos, crenças, sentimentos, valores, interesses, expectativas, aspirações, temores, comportamento presente ou passado etc.

Na sequência estão apresentadas as informações decorrentes da pesquisa, bem como a análise dela. Iniciaremos a análise apresentando o perfil dos sujeitos da pesquisa, ou seja, duas professoras, que, com o intuito de manter a identidade preservada, serão caracterizadas neste estudo como professora $\mathrm{A}$ e professora $\mathrm{B}$. No que compete à formação acadêmica, a professora $\mathrm{A}$ é formada em Licenciatura em Artes Visuais e Magistério (ensino médio), e, há nove anos, atua

10 Para Severino (2007), o método científico racional positivista da origem a ciência, racionalista limitando-se relação funcional de causa a efeito, sendo medida através de uma função matemática. Esse modelo era adequado na produção de ciência, relacionada ao mundo físico, mas com o tempo os cientistas perceberam que para a compreensão do mundo humano, o método não era tão eficaz. 
como professora alfabetizadora da EJA e dez como professora. Já a professora B, é formada em Licenciatura em Pedagogia, atuando há três anos como professora alfabetizadora da EJA e possui experiência de oito anos como professora.

Para apresentar os resultados da pesquisa realizada foram criadas seis categorias, as quais emergiram das questões apresentadas às professoras: "o que você entende por alfabetização?"; "Qual o perfil da turma de estudantes em que você atua?"; "Como trabalhar com perfis distintos em turmas de EJA?"; "Você acredita que o aumento do número de jovens nas salas de aula pode prejudicar o trabalho docente? Justifique"; "Como você percebe a relação dos jovens e adultos dentro da sala de aula?"; e "Como a juvenilização pode afetar/influenciar o processo de alfabetização de jovens e adultos?”. Destacamos que a análise dos dados foi pautada na análise de conteúdo (BARDIN, 2016).

Como forma de organização, tais categorias e seus resultados estão apresentados, neste estudo, em quadros:

Quadro 1 - Categoria 1: conceito de alfabetização

\begin{tabular}{|l|l|}
\hline Professora: & \multicolumn{1}{c|}{ Resposta } \\
\hline A & $\begin{array}{l}\text { Consiste no processo de aprendizagem do uso dos códigos linguísticos falados e escritos } \\
\text { visando à comunicação. }\end{array}$ \\
\hline B & $\begin{array}{l}\text { Entendo alfabetização como o ato do estudante lê e compreender o que está sendo lido, bem } \\
\text { como poder fazer as devidas intervenções sobre o texto lido. }\end{array}$ \\
\hline
\end{tabular}

Fonte: Elaborado pelos autores.

Esse primeiro quadro já apresenta uma questão relevante para a análise da pesquisa, pois podemos perceber, através das respostas apresentadas, que as professoras compreendem a alfabetização de maneiras diferentes. Para a professora B, a alfabetização está sendo considerada de forma mais ampla. Na resposta da professora A, encontramos traços dos conceitos de letramento e alfabetização apresentados por Soares (2004). Para a autora, a alfabetização é a decodificação e codificação da escrita, questão levantada pela professora em sua resposta, e quando ela destaca a comunicação, retomando a ideia do uso social da escrita e leitura. É importante salientar que, para Freire (2011), a alfabetização é mais do que a leitura e escrita de palavras, para o autor, ser alfabetizado é um ato político, pois é a leitura do mundo.

No que compete ao perfil da turma de estudantes da EJA, buscamos investigar o perfil da turma de trabalho das professoras, até para constatar se realmente, apresenta-se um crescente de jovens nas turmas de alfabetização da EJA, da pesquisa emergiram os seguintes dados:

Quadro 2-Categoria 2: perfil da turma

\begin{tabular}{|l|l|}
\hline \multicolumn{1}{|c|}{ Professora: } & \multicolumn{1}{c|}{ Resposta } \\
\hline A & $\begin{array}{l}\text { É uma turma heterogênea formada por jovens e adultos. Sendo que entre os jovens } \\
\text { existem estudantes com laudos de DI, deficiência intelectual e TGD, transtorno global } \\
\text { do desenvolvimento. }\end{array}$ \\
\hline B & $\begin{array}{l}\text { O perfil da turma que atuo são de adultos em idade superior a 30 anos na sua grande } \\
\text { maioria, e tem também estudantes com idade inferior a 20 anos, são estudantes } \\
\text { interessados sempre dispostos a aprender, faltas sempre tem, mas eles pedem o que foi } \\
\text { dado na sua ausência. }\end{array}$ \\
\hline
\end{tabular}

Fonte: Elaborado pelos autores.

Pelas respostas das professoras, podemos perceber que os jovens estão presentes nas classes de Educação de Jovens e Adultos, inclusive nas turmas de alfabetização. Como apresenta Trojahn (2014, p. 37): "Outro fator que se destaca é a passagem de estudantes do dia, que já têm quinze 
anos e estão tendo dificuldades em acompanhar a turma na qual se encontram, por problemas disciplinares ou de aprendizagem".

Podemos observar com a citação e relacionando com os relatos das professoras, que muitas vezes a escola acaba por levar para a EJA os estudantes que não se adaptam ao ensino diurno, seja pelo seu comportamento ou pelas dificuldades de aprendizagens apresentadas. Pontes e Clark (2016) abordam, em sua pesquisa, a má-fé institucional relacionada com a EJA. Com isso, eles percebem que:

Pensando na caracterização dos sujeitos da EJA feita na parte introdutória desta discussão, é possível entender que esses sujeitos fazem parte da categoria ralé brasileira. São eles os sujeitos sutilmente convidados a se retirar da escola pública brasileira e que, contraditoriamente, são convocados a retornar. (PONTES; CLARK, 2016, p. 69).

A professora A, em sua resposta, destaca as inclusões, dizendo que: "Sendo que entre os jovens existem estudantes com laudos de DI (deficiência intelectual) e TGD (transtorno global do desenvolvimento)". Trojahn (2014, p. 37-38) ao falar sobre o assunto destaca que:

Casos de inclusão também estão chegando à EJA, o que está deixando os professores cada vez mais angustiados, pois como não existe uma estrutura adequada, em muitas escolas, para um trabalho de apoio ao professor e principalmente ao estudante. O professor adapta sua aula de acordo com as necessidades de seu estudante, mas, muitas vezes, isso somente não é suficiente. É preciso apoio especializado fora da escola, formação ao professor, mais horas de apoio pedagógico à noite nas escolas, políticas de encaminhamento ao trabalho por parte do sistema de ensino que mantém as escolas, para que assim possamos fazer realmente um trabalho de inclusão com qualidade.

A Educação de Jovens e Adultos, no Brasil, conforme consta na LDB (BRASIL, 1996), é oportunizada às pessoas que não tiveram acesso ou oportunidade de continuarem seus estudos na idade própria. A ampliação do acesso à escola, bem como das políticas de inclusão, faz com que esses estudantes cheguem à escola em maior número, necessitando, assim, de um atendimento diferenciado e um apoio pedagógico para os professores e estudantes.

No Quadro 3, iremos apresentar como é realizado o trabalho pedagógico pelas professoras, visto a diversidade encontrada na sala de aula.

\section{Quadro 3 - Categoria 3: o trabalho pedagógico com perfis distintos}

\begin{tabular}{|l|l|}
\hline \multicolumn{1}{|c|}{ Professora: } & \multicolumn{1}{c|}{ Resposta } \\
\hline A & $\begin{array}{l}\text { O trabalho nas turmas de alfabetização e pós-alfabetização na EJA necessariamente } \\
\text { tem que ser personalizado, adaptado, ao perfil dos estudantes que compõem a turma. } \\
\text { É possível classificar os estudantes em grupos que se assemelham por terem as mesmas } \\
\text { características, mesmas necessidades educacionais ou mesmos perfis de estilos de } \\
\text { aprendizagens. Este estudo das diferentes necessidades que os estudantes apresentam } \\
\text { deve nortear o currículo do estudante, de forma a se poder adaptar os conteúdos e } \\
\text { as metodologias adequando-os à turma. Muitas vezes há necessidade de planos de } \\
\text { trabalho diferenciados para estudantes distintos na mesma sala de aula, que se desen- } \\
\text { volve concomitantemente. }\end{array}$ \\
\hline B & $\begin{array}{l}\text { Trabalho sempre com dois planos, um para os estudantes mais idosos, que não gostam } \\
\text { de tecnologia e outro para os estudantes mais novos. }\end{array}$ \\
\hline
\end{tabular}

Fonte: Elaborado pelos autores.

Conforme podemos observar no Quadro 3, identificamos que ambas ressaltam a importância de um planejamento diversificado, que venha ao encontro da realidade e necessidade de 
cada estudante. No relato da professora B, percebemos que, para a mesma, a faixa etária acaba por interferir no interesse dos educandos nas atividades planejadas. Carrano (2007, p. 3) apresenta:

Parto do princípio de que muitos dos problemas que os educadores enfrentam nas muitas salas de aula e espaços escolares deste país com os jovens estudantes têm origem em incompreensões sobre os contextos não escolares, os cotidianos e os históricos mais amplos, em que esses estão imersos. Dito de outra forma torna-se cada vez mais improvável que consigamos compreender os processos sociais educativos escolares se não nos apropriarmos dos processos mais amplos de socialização.

Para superar esses problemas, se faz necessário que os professores conheçam a realidade dos seus estudantes, suas trajetórias, dentro e fora dos espaços escolares, ouvir o que eles têm a falar. Além dessa questão, é importante retomar a ideia do autor, sobre a necessidade de pensarmos espaços culturais para os jovens.

Quadro 4-Categoria 4: a juvenilização e a interferência no trabalho docente

\begin{tabular}{|l|l|}
\hline \multicolumn{1}{|c|}{ Professora: } & \multicolumn{1}{c|}{ Resposta } \\
\hline A & $\begin{array}{l}\text { Absolutamente não, apenas o perfil da turma seria de estudantes mais jovens. O } \\
\text { professor tem que adaptar o trabalho de forma a atender a necessidade da turma. }\end{array}$ \\
\hline B & $\begin{array}{l}\text { Sim, porque as escolas ainda têm a visão de transferirem para a EJA os estudantes que } \\
\text { não querem estudar. }\end{array}$ \\
\hline
\end{tabular}

Fonte: Elaborado pelos autores.

Constatamos ideias diferentes nas respostas das professoras, cada uma trazendo consigo a sua visão e realidade vivida no espaço escolar. Para a professora $\mathrm{A}$, a juvenilização não interfere na prática da sala de aula de forma negativa, só fará com que o professor se desacomode e crie metodologias de trabalho diferentes para que assim consiga atender as necessidades da turma que se apresenta a ele. No entanto, a professora B apresenta um relato bastante interessante para a presente pesquisa e para refletirmos o porquê desse movimento de juvenilização da EJA.

Acreditamos que essa visão da professora B, apesar de "chocante", faz parte da realidade vivida no cotidiano de muitas escolas, pois, durante as vivências no campo da educação, escutamos professores fazendo esse tipo de afirmação dentro de escolas, bem como um discurso já pronto para esses jovens, visto como problemáticos, dizendo que se adaptaram melhor na EJA e com outros jovens que apresentam as mesmas características que eles. Soares (2019), apresenta em sua pesquisa, os relatos dos estudantes jovens, de como ocorreu a transição do ensino regular para EJA, eles tiveram dificuldades em relatar como foram encaminhados para a modalidade, nas falas observamos que para os jovens foi uma promoção, semelhante a ser aprovado.

Em nossa pesquisa, percebemos, através dos relatos, que, muitas vezes, os alunos também não tinham interesse em frequentar a EJA Cidadã. Ao contrário do que apresentam os professores, alguns até relatam certo interesse em frequentar a EJA, por conta dos amigos, da sua idade, ou por outros motivos, mas a maioria compreende frequentar a EJA como uma promoção, como ser 'aprovado para EJA'. (SOARES, 2019, p. 61).

Dentre as experiências vivenciadas, refletimos muito essa realidade, pois já convivíamos com essa juvenilização da EJA, e as professoras, que faziam parte das discussões, apresentavam essa realidade, de que as escolas acabavam por fazer esse movimento de "empurrar" os estudantes que indicavam dificuldades de aprendizagens, ou comportamento para a EJA. Essa interação entre jovens e adultos em sala de aula pode ser algo favorável para os dois processos: ensino e aprendizagem. 
Cabe ao professor, enquanto gestor dos processos que acontecem em sala de aula, perceber e administrar conflitos e situações de aprendizagens.

Quadro 5 - Categoria 5: relação entre jovens e adultos em sala de aula

\begin{tabular}{|l|l|}
\hline \multicolumn{1}{|c|}{ Professora: } & \multicolumn{1}{c|}{ Resposta } \\
\hline A & $\begin{array}{l}\text { A diferença de idades não é condição para que haja conflitos. As relações conflituosas } \\
\text { podem ocorrer em quaisquer situaçóes. O mesmo ocorre com as relações de parce- } \\
\text { rias. É preciso trabalhar o sentimento de união nas turmas para que os estudantes se } \\
\text { sintam pertencentes ao grupo numa relação dialética de trocas harmônicas. }\end{array}$ \\
\hline B & $\begin{array}{l}\text { Os estudantes que querem de fato estudar sim, eles se integram, fazem trabalhos e } \\
\text { atividades juntos. }\end{array}$ \\
\hline
\end{tabular}

Fonte: Elaborado pelos autores.

A professora $\mathrm{A}$, faz uma reflexão de que a faixa etária não influencia nos conflitos que possam ocorrer dentro da sala de aula, mesmo sendo que ao elaborar essa pergunta tínhamos como objetivo saber como eles interagiam, não necessariamente estávamos focados em saber a existência de conflitos, mas sim saber se existiam trocas de aprendizagens entre eles. Já na resposta da professora $B$, vemos que, para ela, os estudantes que demonstram interesse em aprender e estudar conseguem fazer essa aproximação com os colegas que apresentam mais idade. A última pergunta presente no questionário buscava verificar se para as professoras a juvenilização poderia influenciar no processo de alfabetização e de que forma isso poderia acontecer.

Quadro 6 - Categoria 6: influência da juvenilização no processo de alfabetização de jovens e adultos

\begin{tabular}{|l|l|}
\hline \multicolumn{1}{|c|}{ Professora: } & \multicolumn{1}{c|}{ Resposta } \\
\hline \multirow{3}{*}{$\mathrm{A}$} & $\begin{array}{l}\text { Depende mais do perfil individual, das características individuais de cada estudante, de } \\
\text { como ele interfere no grupo. Às vezes os adultos são mais infantis ou tem mais compor- } \\
\text { tamento de adolescentes do que os próprios adolescentes que muitas vezes tem maior } \\
\text { comprometimento e demonstram maior conhecimento e respeito pelas regras interiori- } \\
\text { zadas já, do andamento das aulas e funcionamento da escola e das relações interpessoais } \\
\text { inerentes à sala de aula, entre os estudantes e entre professores e estudantes. }\end{array}$ \\
\hline B & $\begin{array}{l}\text { Com certeza, vai dar uma cara nova à EJA, os estudantes ajudam uns aos outros, e isto } \\
\text { só tende a melhorar com o passar dos anos. }\end{array}$ \\
\hline
\end{tabular}

Fonte: Elaborado pelos autores.

Com os dados obtidos através dessa questão, as professoras esclarecem como elas percebem que o aumento no número de jovens na EJA pode afetar o processo de alfabetização. A professora $\mathrm{A}$ retoma a ideia lançada por ela no Quadro número 6, de que a idade dos estudantes não interfere no trabalho que será desenvolvido, mas que as diferenças estão mais ligadas a características individuais.

Podemos discordar dessa afirmação apresentada pela professora A, pois conforme fomos construindo a pesquisa, autores como Carrano (2007) e Brunel (2004), justamente abordam essa questão da necessidade de uma mudança da didática apresentada pelos professores para trabalhar com os jovens, claro que as características pessoais acabam por interferir na forma em que os jovens se adaptam dentro da sala de aula e da escola. Entretanto, o fato de os jovens estarem passando por um momento da vida, que apresenta diversas formas de viver a sua juventude, acarreta a necessidade de elaborar estratégias que façam a inclusão dessa multiplicidade de sujeitos jovens (DAYRELL, 2003; CARRANO, 2007).

Os autores utilizados no artigo apresentam a necessidade de ouvir os estudantes, bem como a professora em questão apresentou em outra pergunta, e ouvir significa aproximar a escola e o 
estudante, "A idade biológica da adolescência termina, mas isso não significa que alguns traços característicos se ausentem em idades futuras" (CARRANO, 2003, p. 115). Para o autor, é essencial a existência de espaços públicos nas cidades que potencializem a identidade juvenil. Nesse sentido, podemos transpor essa discussão para a escola.

Em contrapartida, a professora $\mathrm{B}$ traz à tona a discussão de que o aumento dos jovens na turma de alfabetização dará uma "cara nova" para a Educação de Jovens e Adultos, justamente pela possibilidade de interação entre jovens e adultos. Ademais, vem ao encontro com o pensamento dos autores que fundamentaram este trabalho, pois mudar a "cara" da EJA pode ser considerado para além da "cara" fisicamente falando, pois isso acarreta fundamentalmente mudar também as práticas desenvolvidas.

\section{Considerações finais}

O presente artigo apresentou reflexões sobre a juvenilização em classes de EJA e o processo de alfabetização. Para construir este artigo foi desenvolvida uma pesquisa utilizando autores do campo da EJA e da alfabetização, além da aplicação de um questionário a duas professoras alfabetizadoras de jovens e adultos. O corpus analítico-discursivo obtido através dos autores selecionados e dos questionários aplicados às alfabetizadoras foi de suma importância para que, ao longo do trabalho, fossem traçados um caminho e uma relação entre a juvenilização e a alfabetização.

Tivemos como problema central: "como a juvenilização da Educação de Jovens e Adultos afeta o processo de alfabetização em escolas públicas dos municípios de Canoas (RS) e Porto Alegre (RS)?”. Foi norteado pelo seu objetivo geral: analisar como a juvenilização da EJA pode afetar o processo de alfabetização em duas escolas públicas que oferecem tal modalidade de ensino, nos municípios de Canoas (RS) e Porto Alegre (RS).

Através deste estudo, conseguimos perceber que, no Brasil, as movimentações ideologias e políticas públicas voltadas para a EJA estão sujeitas a dificuldades dos programas no sentido da continuidade nas trocas de governo. Essas campanhas e programas acabam por interferir na construção do conceito de alfabetização na EJA. Por esse motivo, esse artigo buscou também apresentar diferentes conceitos de alfabetização e letramento, bem como alfabetização nesta modalidade de ensino, a partir de diferentes apoios teóricos.

Com a pesquisa de campo, conseguimos abordar questões que buscaram responder o problema que norteou este estudo. Entre elas, podemos ressaltar a questão levantada por uma das professoras sobre o número de alunos de inclusão nas turmas de alfabetização, ressaltado pela professora A: "Sendo que entre os jovens existem estudantes com laudos de DI, deficiência intelectual, e TGD, transtorno global do desenvolvimento". E como essa realidade interfere no processo de alfabetização e escolarização dos estudantes, pois exige que seja repensada a organização e os espaços escolares na EJA.

Outra questão relevante, também apresenta pelas professoras que responderam os questionários, é a necessidade de ser realizada uma adequação do trabalho dos professores, que respeite a diversidade dos estudantes. Encontramos, também, nos relatos uma semelhança com o processo de alfabetização de crianças, quando as professoras abordaram a necessidade de serem realizados planos diferenciados, de acordo com a realidade de cada estudante.

As professoras levantaram, em momentos distintos, questões relacionadas ao comportamento dos estudantes, bem como, as regras estarem internalizadas com mais facilidade entre os jovens. Ao analisarmos essas questões, percebemos que a escola acaba fazendo uma aproximação dos estudantes que apresentam dificuldades de disciplina, ou aprendizagem para a EJA e o fato dos jovens estarem até pouco tempo na escola regular faz com que as regras e combinações escolares estejam mais presentes nos seus cotidianos do que os adultos que estiveram afastados por mais tempo. 
Dessa forma, destacamos algumas considerações que podemos chegar ao término desta pesquisa, como a necessidade de diálogo e escuta nas aulas de alfabetização na EJA; que na ação da escuta, os professores possam acolher seus estudantes, percebendo-os como sujeitos da aprendizagem, respeitando e contribuindo para a formação de cada um dos educandos. No que diz respeito à prática pedagógica dos docentes sujeitos da pesquisa, em uma de suas respostas, a professora $\mathrm{A}$ apresentou a necessidade de trabalhar com os estudantes através do diálogo e com o conceito de união, para que assim eles construam na escola um espaço de troca e emancipação. Ainda neste sentido, entendemos que a prática pedagógica reflexiva pode contribuir com processos de ensino e aprendizagem que contemplem e respeitem as diversidades dos modos de ser jovem.

As professoras consideram e enfatizam questões internas, possibilidades cognitivas, de dificuldades de aprendizagem, porém tratam com indiferença a condição juvenil. Tão pouco levam em conta a necessidade educacional de aproximação da realidade dos jovens ao contexto escolar. Carrano (2003, p. 18) salienta a necessidade de pensarmos a educação como práticas sociais, pois para o autor isso significa o reconhecimento dos múltiplos fatores que influenciam na construção das identidades. Ao encontro desse pensamento, para as discussões de educação formal, não formal e informal "são rígidas demais para dar conta da mobilidade do processo social", por entender que a educação não se resume aos cotidianos institucionais.

À guisa de uma conclusão, finalizamos este artigo, reafirmando e utilizando uma das frases da professora $B$, ao responder como a juvenilização pode afetar o processo de alfabetização na EJA, "Com certeza, vai dar uma cara nova à EJA, os estudantes ajudam uns aos outros, e isto só tende a melhorar com o passar dos anos". Apesar de a professora ter focado nas trocas vivenciadas pelos estudantes de diferentes faixas etárias, por meio deste estudo foi possível concluir que essa mudança, ou seja, a juvenilização, não se refere somente à faixa etária, mas sim, na oportunidade de alterações inclusive nas práticas educativas, tornando-as mais significativas para o grupo que ali integra a classe de alfabetização, transformando a escola em espaços culturais. De acordo com Carrano (2007), são espaços que aproximam os jovens da escola.

Isto posto, reafirmamos a necessidade de que os professores conheçam e reconheçam a juventude não como um momento da vida determinado por datas, mas sim, como parte de um processo de crescimento totalizante, criando contornos através das vivências dos jovens (DAYRELL, 2003). Não existe uma única forma de ser jovem, por isso o conceito de juventudes no plural, enfatizando os diversos modos de ser jovem, conceito para nós, se torna fundamental para a compreensão dos desafios da juvenilização da EJA no processo de alfabetização.

\section{Referências}

ALBUQUERQUE, Eliana. Concepções de alfabetização: o que ensinar no ciclo de alfabetização. In: BRASIL. Pacto Nacional pela Alfabetização na Idade Certa: caderno de formação ano 1, unidade 1, Brasília, DF: Ministério da Educação (MEC), 2012. p. 16-23. Disponível em: https://wp.ufpel.edu.br/obeducpacto/files/2019/08/Unidade-1.pdf. Acesso em: 13 jan. 2021.

ALVES, Evandro; COMERLATO, Denise; SANT’ANA, Sita. Relatório de pesquisa 2017: mapa da Educação de Jovens e Adultos no Estado do Rio Grande do Sul. Porto Alegre: NIEPE-EJA/UFRGS, 2017. Disponível em: https://www.lume. ufrgs.br/bitstream/handle/10183/173114/001060717.pdf?sequence=1. Acesso em: 13 jan. 2021.

ANDRÉ, Marli. Pesquisa em Educação: buscando rigor e qualidade. Cadernos de Pesquisa, São Paulo, n. 113, p. 51-64, jul. 2001. BARDIN, Laurence. Análise de Conteúdo. São Paulo: Edições 70, 2016.

BRANDÃO, Carlos Rodrigues. O que é educação Popular. São Paulo: Editora Brasiliense, 1984.

BRASIL. Censo Escolar. Brasília, DF: Instituto Nacional de Estudos e Pesquisas Educacionais Anísio Teixeira, 2018. 
BRASIL. Lei no 12.852, de 5 de agosto de 2013. Estatuto da Juventude. Diário Oficial da União, Brasília, DF, 2013. Disponível em: http://www.planalto.gov.br/ccivil_03/_ato2011-2014/2013/lei/112852.htm. Acesso em: 13 jan. 2021.

BRASIL. Lei no 9.394, de 20 de dezembro de 1996. Estabelece as diretrizes e bases da educação nacional. Brasília, DF: Presidência da República, 1996. Disponível em: http://www.planalto.gov.br/ccivil_03/leis/19394.htm. Acesso em: 14 jan. 2021.

BRASIL. Trabalhando com a Educação de Jovens e Adultos: Aluna e Estudantes da EJA.

Brasília, DF: SECAD, 2006. Disponível em: http://portal.mec.gov.br/secad/arquivos/pdf/eja_cadernol.pdf. Acesso em: 13 jan. 2021.

BRUNEL, Carmen. Jovens cada vez mais jovens na educação de jovens e adultos. Porto Alegre: Mediação, 2004.

CARRANO, Paulo. Juventudes e Cidades Educadoras. Petrópolis: Vozes, 2003.

CARRANO, Paulo. Educação de Jovens e Adultos e Juventude: o desafio de compreender os sentidos da presença dos jovens na escola da "segunda chance”. REVEJ@: Revista de Educação de Jovens e Adultos, Belo Horizonte, v. 1, n. 0, 2007.

DAYRELL, Juarez. O jovem como sujeito social. Revista Brasileira de Educação, Rio de Janeiro, n. 24, p. 40-52, set./dez. 2003.

FONSECA, Laura. Na prática de ensino, pesquisas em Educação de Jovens e Adultos. Aprendendo com Jovens e Adultos - NIEPE, Porto Alegre, ano 2, n. 1, dez. 2001.

FREIRE, Paulo. Educação como Prática da Liberdade. Rio de Janeiro: Editora Paz e Terra, 1983.

FREIRE, Paulo. Pedagogia da Autonomia: saberes necessários à pratica educativa. São Paulo: Paz e Terra, 1996.

FREIRE, Paulo. A importância do ato de ler: em três artigos que se completam. 51. ed. São Paulo: Cortez, 2011.

GIL, Antônio. Métodos e técnicas de pesquisa social. 6. ed. São Paulo: Atlas, 2008.

INSTITUTO BRASILEIRO DE GEOGRAFIA E ESTATÍSTICA (IBGE). Pesquisa nacional por amostra de domicílios contínua: PNAD. Rio de Janeiro: IBGE, 2018. Disponível em: https://biblioteca.ibge.gov.br/visualizacao/livros/ liv101576_informativo.pdf. Acesso em: 13 jan. 2021.

KALMAN, Judith. O acesso à cultura escrita: a participação social e apropriação de conhecimentos em eventos cotidianos de leitura e escrita. In: PAIVA, Jane; OLIVEIRA, Inês Barbosa de (org.). Educação de jovens e adultos. Petrópolis: DP\&A, 2009. p. 72-95.

LEMOS, Amanda. Entre teorias e práticas: o trabalho alfabetizador na EJA. In: SOUZA, Marta (org.). Educação de jovens e adultos: linguagens, alfabetizações e afetos. 1. ed. Rio de Janeiro: Letra Capital, 2020. p. 15-28.

LEMOS, Amanda. "Despeja na EJA": reflexões acerca da migração perversa de jovens para o PEJA no município do Rio de Janeiro. 2017. Dissertação (Mestrado em Educação) - Universidade Federal do Estado do Rio de Janeiro, Rio de Janeiro, 2017.

MORAES, Salete. Alunos diferentes e saberes docentes. In: CHRISTOFOLI, Maria Conceição Pillon et al. EJA: planejamento, metodologias e avaliação. Porto Alegre: Mediação, 2009. p. 89-98.

NAJMANOVICH, Denise. O feitiço do método. In: GARCIA, Regina Leite (org.). Método, métodos e contramétodo. São Paulo: Cortez, 2003. p. 25-62.

ORGANIZAÇÃO DOS ESTADOS IBERO-AMERICANOS PARA A EDUCAÇÃO, A CIÊNCIA E A CULTURA (OEI). A Educação que queremos para a geração dos bicentenários: Metas Educativas 2021. Madri: OEI, 2008. Disponível em: http://www.oei.es/metas2021/indicep.htm. Acesso em: 17 jul. 2019.

PICOLLI, Luciana; CAMINI, Patrícia. Práticas pedagógicas em alfabetização: espaço, tempo e corporeidade. Erechim: Edelbra, 2012.

PONTES, Edmundo Marcos Ferreira; CLARK, Georgia Nelly. A má-fé institucional a Educação de Jovens e Adultos no Brasil. Revista Brasileira de Educação de Jovens e Adultos, Salvador, v. 4, n. 7, 2016.

SANTOS, Guilherme Mendes Tomaz dos. A qualidade da educação superior e a pedagogia universitária: um olhar sobre a docência. 2018. Tese (Doutorado em Educação) - Universidade La Salle, Canoas, 2018.

SEVERINO, Antônio Joaquim. Metodologia do trabalho científico. 23. ed. São Paulo: Cortez, 2007.

SILVA, Jaqueline. Letramento: uma prática em busca da (re) leitura do mundo. Rio de Janeiro: Wak Editora, 2009. 
SOARES, Deivid. Os jovens e o funk na educação de jovens e adultos: (im)possibilidades de diálogo intercultural. 2019. Dissertação (Mestrado em Educação) - Universidade LaSalle, Canoas, 2019.

SOARES, Leôncio. Educação de Jovens e Adultos: Diretrizes Curriculares Nacionais. Rio de Janeiro: DP\&A, 2002.

SOARES, Magda. Letramento e alfabetização: as muitas facetas. Revista Brasileira de Educação, Rio de Janeiro, n. 25, p. 5-17, jan./abr. 2004.

TROJAHN, Luciane de Melo Gonçalves. EJA: totalidade inicial 1 - experiência pedagógica e de vida. ÁGORA, Porto Alegre, ano 5, p. 36-45, dez. 2014.

UNESCO. Declaração Universal dos Direitos Humanos. São Paulo: UNESCO, 1948.

UNESCO. Declaração de Dakar. Educação para Todos. Senegal: UNESCO, 2000.

UNESCO. Educação 2030: Declaração de Incheon e Marco de Ação: rumo a uma educação de qualidade inclusiva e equitativa e à educação ao longo da vida para todos. Brasília, DF: UNESCO, 2015.

VIEIRA, Roxo Lívia. Como é bom ser vida loka: Juventude, escola e o consumo musical do funk. 2012. Trabalho de Conclusão de Curso (Curso de Pedagogia) - Faculdade de Educação, Universidade Federal do Rio Grande do Sul, Porto Alegre, 2012.

Data de submissão: $31 / 01 / 2021$

Data de aceite: 09/02/2021 